\title{
Quantum Chemical Determination of Young's Modulus of Lignin. Calculations on a $\beta-0-4^{\prime}$ Model Compound
}

\author{
Thomas Elder* \\ Research Forest Products Technologist, USDA-Forest Service, Southern Research Station, 2500 \\ Shreveport Highway, Pineville, Louisiana 71360
}

Received June 13, 2007; Revised Manuscript Received August 23, 2007

\begin{abstract}
The calculation of Young's modulus of lignin has been examined by subjecting a dimeric model compound to strain, coupled with the determination of energy and stress. The computational results, derived from quantum chemical calculations, are in agreement with available experimental results. Changes in geometry indicate that modifications in dihedral angles occur in response to linear strain. At larger levels of strain, bond rupture is evidenced by abrupt changes in energy, structure, and charge. Based on the current calculations, the bond scission may be occurring through a homolytic reaction between aliphatic carbon atoms. These results may have implications in the reactivity of lignin especially when subjected to processing methods that place large mechanical forces on the structure.
\end{abstract}

\section{Introduction}

Lignin is an amorphous aromatic polymer occurring in plant materials and some fungi. Among natural polymers, lignin is second only to cellulose in global abundance, representing 30\% of all carbon bound in organic matter on earth. ${ }^{1}$ Making up approximately $25 \%$ of the woody cell wall, the hydrophobic nature of lignin is critical for moisture relations; its presence in terrestrial plants is thought to provide the mechanical properties needed to overcome gravitational stresses; and it imparts resistance to attack by microorganisms. ${ }^{2}$ The presence of lignin is critical in structural applications of wood, and its removal is an essential step in the pulping and bleaching processes of paper manufacture. Lignin polymerization begins with the enzymatic dehydrogenation of $p$-coumaryl alcohol, coniferyl alcohol, and sinapyl alcohol, which generates a free radical that may exhibit several coupling modes, resulting in a polymer with a number of intermonomer linkages, and lacking a specific monomeric repeat unit. ${ }^{2}$ Among the most common interunit connections are the $\beta-\mathrm{O}-4^{\prime}, \beta-\beta, \beta-5^{\prime}, 5-5^{\prime}$, and dibenzodioxocin linkages, the first of which is responsible for approximately $50 \%$ of the connections in the polymer (Figure 1) and will be the subject of the current study.

The mechanical properties of the woody cell wall and the cellulose of which it is primarily composed (ca. 50\%) have been the subject of both experimental and theoretical analyses. The latter dates back to $1936,{ }^{3}$ with considerable intervening work carried out by Gillis and co-workers. ${ }^{4,5}$ In the more recent literature, this problem has been addressed using contemporary methods in molecular modeling, ${ }^{6-9}$ resulting in values for Young's modulus of cellulose ranging from 36 to $130 \mathrm{GPa}$. This fundamental material property for objects under uniaxial load is described by a direct proportion between load and deformation, in which Young's modulus is the proportionality constant. ${ }^{10}$

* Corresponding author. Telephone: (318) 473-7008. Fax: (318) 473 7246. E-mail: telder@fs.fed.us.

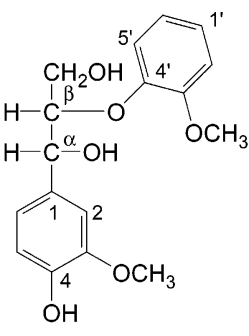

(a)

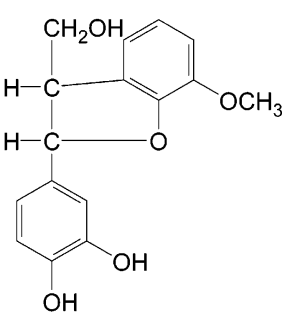

(b)<smiles>COc1cc(C2OCC3COCC(CO3)C2c2ccc(O)c(OC)c2)ccc1O</smiles>

(c)<smiles>COc1cc(/C=C/CO)cc(-c2cc(/C=C/CO)cc(OC)c2O)c1O</smiles>

(d)<smiles>COc1cc(C2Oc3c(OC)cc(/C=C/CO)cc3-c3cc(/C=C/CO)cc(OC)c3OC(CO)C2O)ccc1O</smiles>

(e)

Figure 1. Principal interunit linkages in lignin: (a) $\beta-0-4^{\prime}$, (b) $\beta-5^{\prime}$, (c) $\beta-\beta^{\prime}$, (d) $5-5^{\prime}$, (e) dibenzodioxocin. 
In contrast to the several literature sources addressing the elasticity of cellulose, analogous information about lignin is generally less available. This is probably due to the difficulties associated with the isolation of lignin and the changes in chemistry and structure inherent in any isolation process. In early experimental work, Srinivasan ${ }^{11}$ molded cylindrical samples of powdered lignin, resulting in a Young's modulus of 2.0 GPa. Cousins and co-workers ${ }^{12,13}$ using periodate lignin found values from 3.1 to $6.7 \mathrm{GPa}$, depending on the moisture content of the samples. Using nanoindentation on the cell corner compound middle lamella, a region of the woody cell wall with a very high lignin percentage, an average value of $6.8 \mathrm{GPa}$ has been found, ${ }^{14}$ while Salmén uses a value of $2.0 \mathrm{GPa} .{ }^{15}$ A synthetic resin used in dental composites, and a phenol-formaldehyde resin, both of which bear some degree of structural similarity to lignin, are reported to have Young's moduli of about 4.8 $\mathrm{GPa}^{16}$ and $7.6 \mathrm{GPa},{ }^{17}$ respectively.

Given the issues that may be encountered in experimental work of this nature, the objective of the current Article is to calculate Young's modulus for lignin based on the $\beta-\mathrm{O}-4^{\prime}$ lignin model compound, using computational chemical methods. While, as discussed, the lignin polymer may contain numerous interunit linkages, the $\beta-\mathrm{O}-4^{\prime}$ occurs with the most frequency and will be used as a starting point for this work. The calculations to be employed will be semiempirical, ab initio, and density functional methods, analogous to the literature on cellulose and synthetic polymers. ${ }^{7,18,19}$ Although more timeconsuming than classical mechanical techniques, these more rigorous methods can be used to examine bond breaking ${ }^{7}$ and the associated electronic changes, indicative of chemical modifications that occur upon strain, as proposed in the literature. ${ }^{20}$ In this work, the structure will be deformed in tension, and the corresponding energies, stresses, geometric, and electronic modifications that occur will be determined.

\section{Materials and Methods}

While the lignin polymer is noncrystalline, a large number of lignin model compounds have been prepared synthetically and characterized by X-ray crystallography. As such, an available X-ray structure will be used as the starting point for the current work on a dimer with a $\beta-\mathrm{O}-4^{\prime}$ linkage (Cambridge Structural Database Entry RABWUM). ${ }^{21}$ The structure to be considered and the numbering scheme are as shown in Figure 1a.

Calculations were performed on isolated, gas-phase molecules at 0 $\mathrm{K}$ with the semiempirical AM1 parametrization, ab initio HartreeFock calculations using the $3-21 \mathrm{G}^{*}$ and $6-31 \mathrm{G}^{*}$ basis sets, and density functional B3LYP/6-31G* calculations using Spartan. ${ }^{22}$ The relative performance of computational methods has been evaluated in the recent literature ${ }^{23}$ in which it was reported that for moderate sized basis sets (3-21G*, 6-31G*, 6-311G*) Hartree-Fock calculations provided more accurate bond length results than did B3LYP. Accuracy can be improved by the use of more extensive basis sets, and within a basis set by the inclusion of electron correlation. This is in contrast to the conclusions of $\mathrm{Hehre}^{24}$ in which correlation was not found to offer a major advantage for the determination of equilibrium geometries. Young $^{25}$ has tabulated results for a number of basis sets and model chemistries, reporting root-mean-square errors of 0.048, 0.032, 0.032, and 0.020 for bond lengths for AM1, HF/3-21G*, HF/6-31G*, and B3LYP/6-31G*, respectively. In a study on a mono- and disaccharide, it was reported that AM1 and $\mathrm{HF} / 6-31 \mathrm{G}^{*}$ resulted in similar structural results. ${ }^{26}$ Among the methods used in the current Article, B3LYP/6$31 \mathrm{G}^{*}$ is the most accurate for the determination of energies, followed by AM1, with much larger errors from the Hartree-Fock calculations. ${ }^{25}$ The current study is not intended to be a systematic examination of computational methods, or a documentation of differences between theory and experiment. The range of methods was used to reinforce the results, rather than rely on a single technique.

The initial crystallographic structure was optimized with each of the computational methods. Next, the distance between $\mathrm{C} 4$ and $\mathrm{C1}^{\prime}$, representing the ends of the structure, was increased by a total of 5\% in 10 increments, such that the dimer is being strained in tension, with all other variables optimized at each step. A perusal of the literature will reveal that in similar studies results in both compression and tension have been reported. ${ }^{6,7}$ Generally, however, this yields a symmetric curve for energy as a function of strain, such that in the current work calculations were limited to tensile measurements. The energy (in joules) at each step was plotted as a function of distance (in meters), resulting in a curve that could be fitted with a second-order polynomial function. The first derivative of this function was taken, from which forces at each point were determined. The cross-sectional area of the structure was based on the unit cell, for which the " $a$ " dimension is $5.08 \AA$ and the " $b$ " dimension is $30.11 \AA$. Given that each structure within the crystal lattice is surrounded by four other molecules, the final size is determined as $5.08 *(30.11 / 4)=38 \AA^{2}$. The stress at each point is determined as the force divided by the cross-sectional area. The slope of the linear stress versus strain $\left(d_{\mathrm{i}}-d_{0} / d_{0}\right)$ relationship is Young's modulus or modulus of elasticity.

In addition, for each point and computational method, geometric variables associated with the interunit linkage were evaluated. It might be predicted that as the structure is deformed, it is these connections that will undergo larger and more informative changes, especially in comparison, for example, to the bonds within the aromatic rings.

The values measured were bond lengths $(\mathrm{C} 1-\alpha, \alpha-\beta, \beta-\mathrm{O}$, and $\left.\mathrm{O}-\mathrm{C}^{\prime}{ }^{\prime}\right)$, bond angles $\left(\mathrm{C} 1-\alpha-\beta, \alpha-\beta-\mathrm{O}\right.$, and $\left.\beta-\mathrm{O}-\mathrm{C}^{\prime}\right)$, and dihedral angles $\left(\mathrm{C} 2-\mathrm{C} 1-\alpha-\beta, \mathrm{C} 1-\alpha-\beta-\mathrm{O}, \alpha-\beta-\mathrm{O}-\mathrm{C}^{\prime}\right.$, and $\left.\beta-\mathrm{O}-\mathrm{C} 4^{\prime}-\mathrm{C} 5^{\prime}\right)$. Other properties assessed were the frontier molecular orbital energies and Mulliken charges for $\mathrm{C}-\alpha, \mathrm{C}-\beta$, and the oxygen atom for each conformation and calculation.

Subsequently, a second set of calculations was performed to a strain level of $75 \%$ in 45 steps to determine if bond breakage could be observed. Because of the larger number of calculations, this phase of the work was limited to the AM1 method.

\section{Results}

Energy, Stress, Strain, and Young's Modulus. The energies of the $\beta-\mathrm{O}-4^{\prime}$ dimer, as a function of strain, exhibiting polynomial relationships are shown for each method in Figure 2a. Stress/strain diagrams are shown in Figure 2b, resulting in values for Young's modulus of 2.31 GPa (AM1), 3.65 GPa (HF/ 3-21G*), 3.41 GPa (HF/6-31G*), and 4.65 GPa (B3LYP/6$\left.31 \mathrm{G}^{*}\right)$. These values are consistent with each other and not dissimilar to the experimental values reported in the literature. This similarity may be due to the prevalence of the $\beta-\mathrm{O}-4^{\prime}$ bond type in the lignin polymer, which is reported to account for from $50 \%$ to $60 \%$ of the interunit linkages.

Geometric Descriptors. Typically, large amounts of energy are required to alter bond lengths and angles, while rotations about dihedral angles occur much more readily. Although, as might be expected, changes in bond lengths due to an overall stretching of the molecule are small $(\sim 1 \%)$, some consistent patterns begin to emerge. Plots of $\Delta L / L_{0}$ (where $\Delta L=L_{\mathrm{i}}-L_{0}$ ) as a function of strain are shown in Figure 3. It can be seen that this value generally increases, albeit somewhat variably, as the structure is strained, with the HF/3-21G* and B3LYP/ 6-31G* calculations consistently the highest in this regard, HF/ 6-31G* intermediate, and the AM1 results the lowest.

Changes in bond angle (calculated as $\Delta \theta / \theta_{0}=\theta_{\mathrm{i}}-\theta_{0} / \theta_{0}$ ) are as shown in Figure 4. The $\mathrm{C} 1-\alpha-\beta$ angle exhibits a reasonably large and linear increase with strain. The changes 

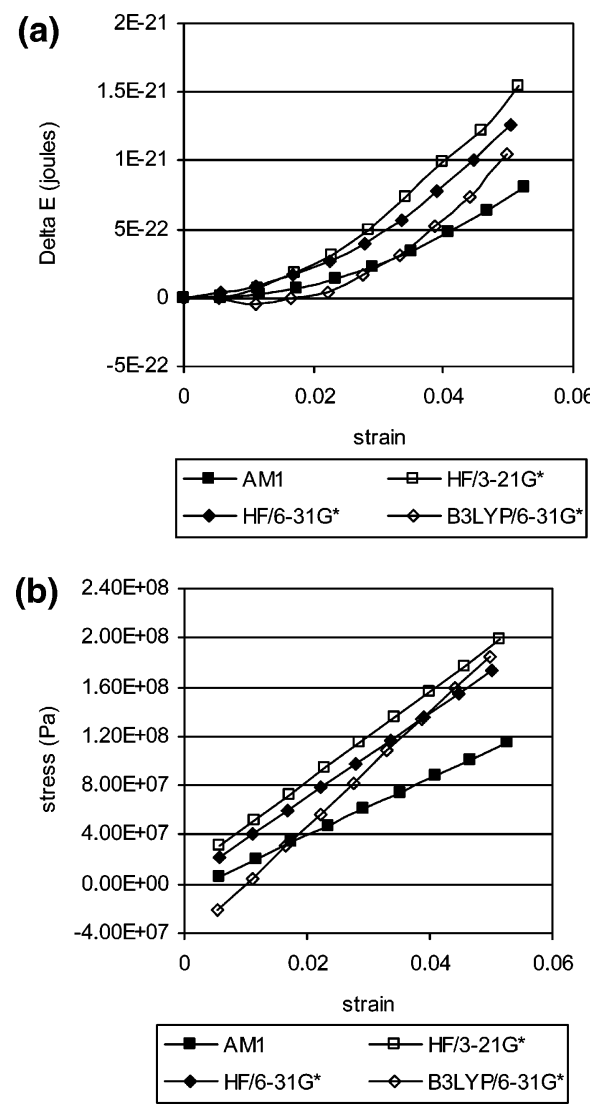

Figure 2. (a) Energy versus strain, (b) stress versus strain, where Young's modulus results (in GPa) are 2.31 (AM1), $3.65 \mathrm{GPa}$ (HF/3$\left.21 \mathrm{G}^{*}\right)$, $3.41\left(\mathrm{HF} / 6-31 \mathrm{G}^{*}\right)$, and $4.65\left(\mathrm{~B} 3 \mathrm{LYP} / 6-31 \mathrm{G}^{*}\right)$.

in the $\alpha-\beta-\mathrm{O}$ and $\beta-\mathrm{O}-\mathrm{C}^{\prime}$ angles are very small in comparison with the $\mathrm{C} 1-\alpha-\beta$, indicating relative insensitivity to changes in the overall molecular structure. Conversely, the
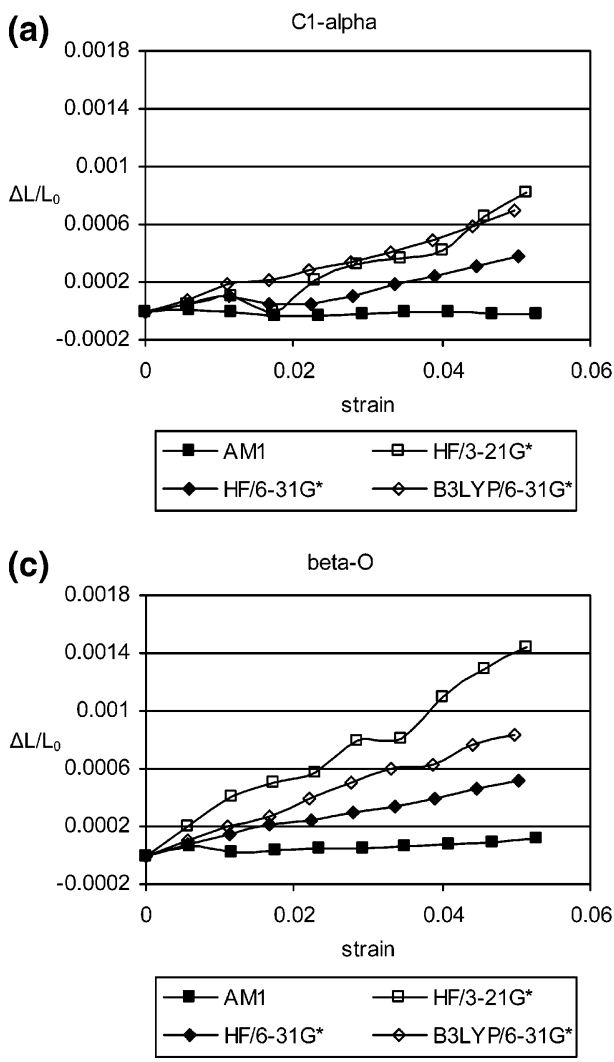

linear relationship of the $\mathrm{C} 1-\alpha-\beta$ angle to the strain would show that this term is closely coupled to the stretching behavior. This may not be overly surprising, given the structure of this dimer and the atoms that were selected to represent the stretch. Because of the connectivity between the aromatic rings, a linear distortion between atoms on each ring can be translated into a bend, such as would occur in a hinged structure. Furthermore, for the $\mathrm{C} 1-\alpha-\beta$ angle, the performance of the computational methods is analogous to that observed for the bond lengths, with $\mathrm{HF} / 3-21 \mathrm{G}^{*}$ and B3LYP/6-31G* providing similar results, HF/6-31G* intermediate, and AM1 exhibiting the smallest changes as a function of strain.

Dihedral angle differences $\left(\Delta \varphi / \varphi_{0}=\varphi_{\mathrm{i}}-\varphi_{0} / \varphi_{0}\right)$ are shown in Figure 5. The $\mathrm{C} 2-\mathrm{C} 1-\alpha-\beta$ and $\mathrm{C} 1-\alpha-\beta-\mathrm{O}$ angles increase with strain, while the $\alpha-\beta-\mathrm{O}-\mathrm{C} 4^{\prime}$ and $\beta-\mathrm{O}-\mathrm{C}^{\prime}-$ $\mathrm{C}^{\prime}$ values decrease. It is interesting that the $\alpha-\beta-\mathrm{O}-\mathrm{C} 4^{\prime}$ dihedral varies quite linearly with strain, similar to the $\mathrm{C} 1-$ $\alpha-\beta$ bond angle. Furthermore, it becomes readily apparent that dihedral angle rotations are much larger (on the order of $4 \%$ ) in comparison to the bond lengths and angles (less than 1\%).

Mulliken Charge and Frontier Orbital Energies. Measures of changes in orbital energies and electronic structure reported are the HOMO and LUMO energies and Mulliken charges for the $\alpha$ and $\beta$ carbons and the oxygen in the interunit linkage. It must, of course, be borne in mind that Mulliken charges are not quantum mechanically determined, but rather the product of a population analysis, which assumes equal orbital overlap. As such, these values should be used with caution as relative measures of charge. These results are shown in Figures 6 and 7. Because the level of strain is small, the changes in these parameters are correspondingly small, but in some cases show definite trends.

Frontier molecular orbital energies vary considerably depending on the calculation that is used, such that $\Delta E\left(E_{\mathrm{i}}-E_{0}\right)$ values are reported in Figure 6. These results are similar for all of the

(b)
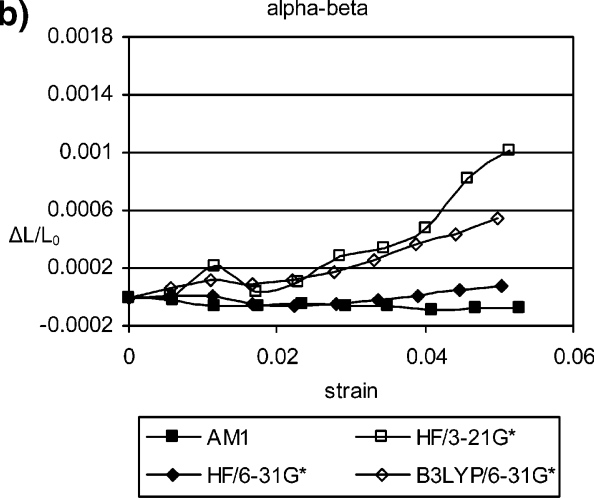

(d)

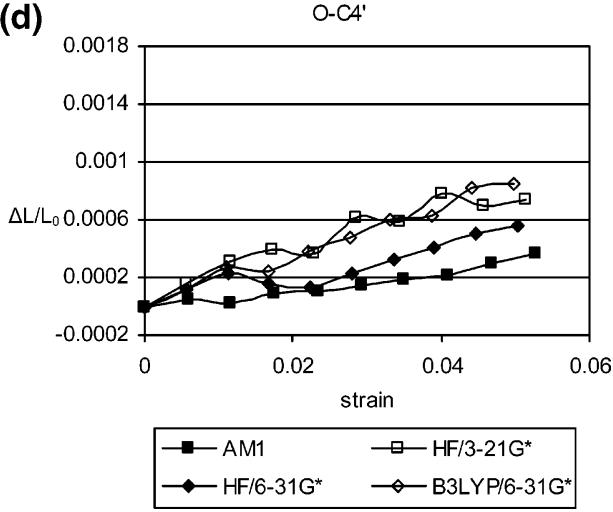

Figure 3. Change in bond length as a function of strain. 
(a)

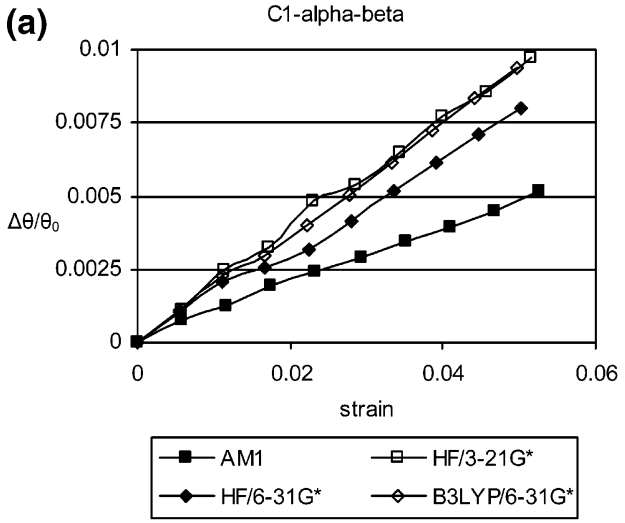

(b)

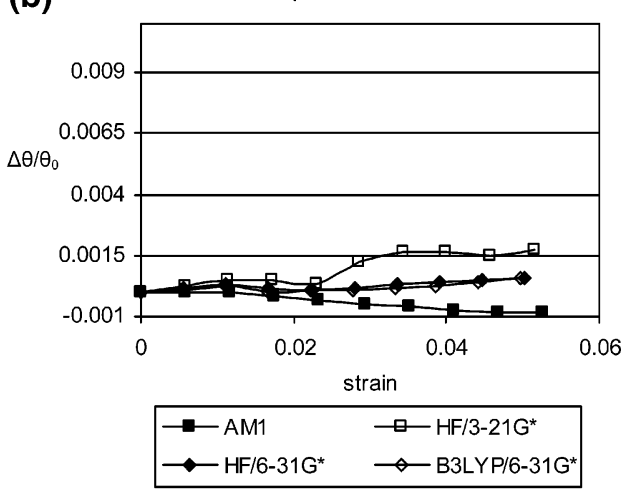

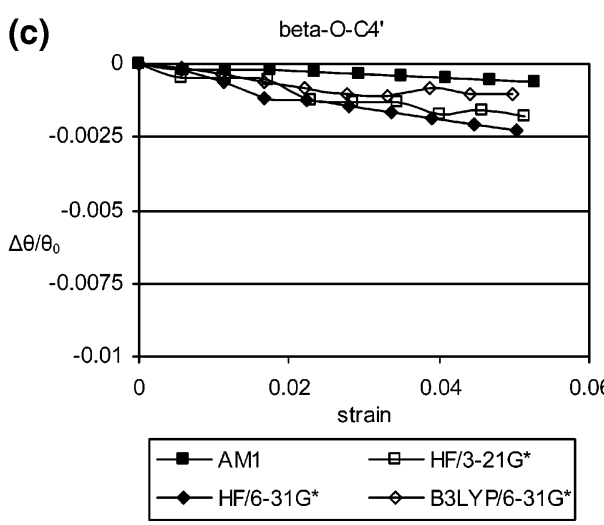

Figure 4. Change in bond angle as a function of strain.

(a)

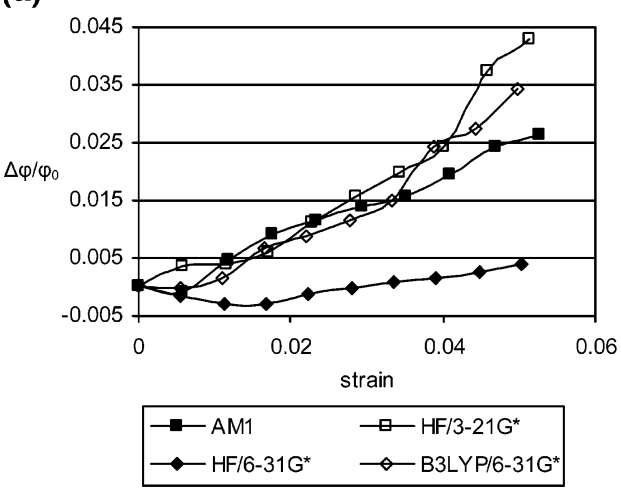

(c)

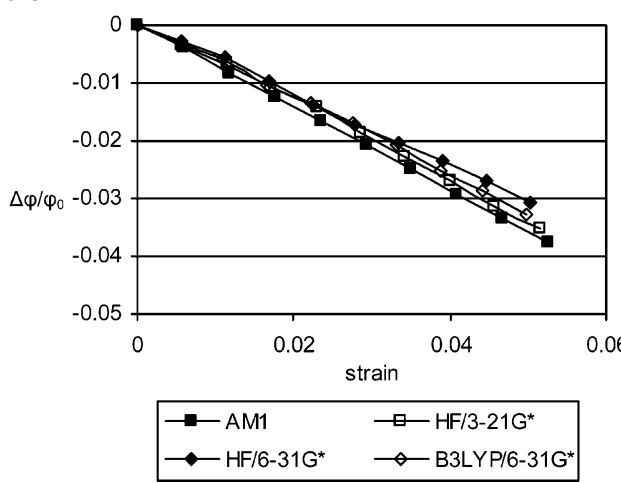

Figure 5. Change in dihedral angle as a function of strain.

calculations with the HOMO energies increasing, while the LUMO energies decrease as a function of strain. Within the HOMO energies, a consistent linear increase is observed for all computational methods except HF/3-21G*. In contrast, the (b)

C1-alpha-beta-O

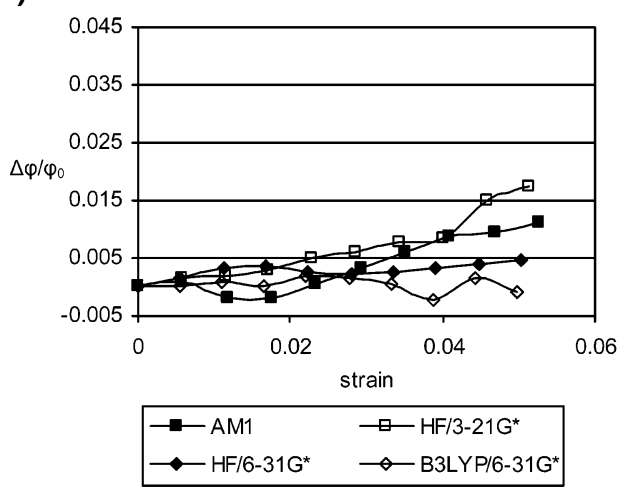

(d)

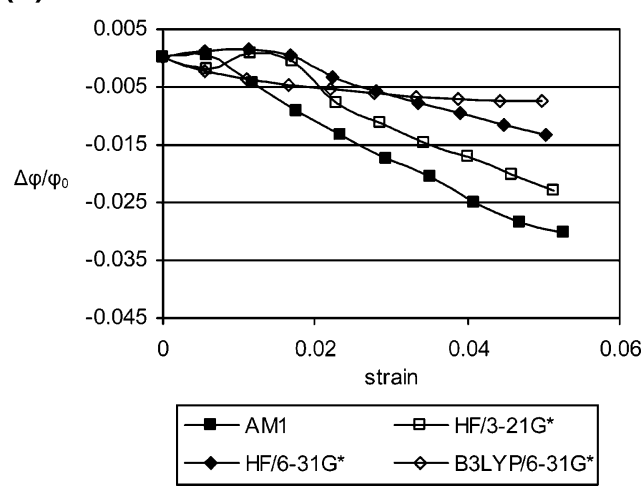

LUMO energies all decrease linearly, albeit with different rates of change depending on the method.

While the frontier molecular orbital energies exhibit reasonably linear and consistent relationships, the Mulliken population 


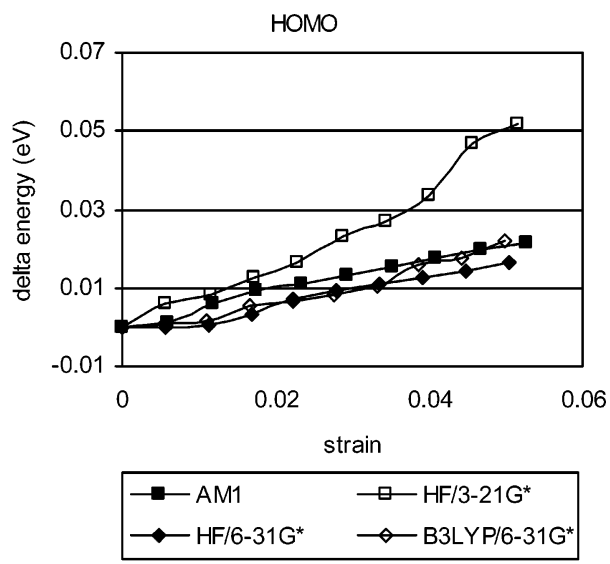

(a)

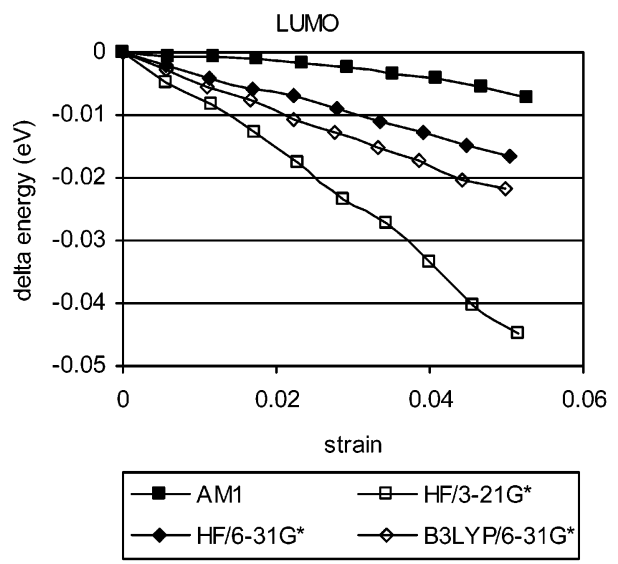

(b)

Figure 6. Changes in frontier molecular orbital energies as a function of strain.

analyses are quite variable with respect to both strain and computational method (Figure 7). The relative charge, $\Delta q\left(q_{\mathrm{i}}\right.$ $-q_{0}$ ), on the oxygen atom increases linearly with strain, except for the B3LYP/6-31G* results, which are much smaller and quite flat. The AM1, HF/3-21G*, and B3LYP/6-31G* calculations indicate that the charge on $\alpha$-carbon is increasing with strain, whereas HF/6-31G* shows a very slight decrease. The $\beta$-carbon results are quite inconsistent between computational methods. The AM1 values fluctuate wildly, while the HF/321G* and B3LYP/6-31G* values decrease with strain. The HF/ 6-31G* results show a slight increase with strain. Systematic comparisons of results from charge calculations in the literature ${ }^{24}$ reveal that differences do occur among the various methods, but provide little insight into which is most appropriate.

75\% Strain. As discussed in the literature, ${ }^{7}$ one of the advantages of using quantum mechanical methods over classical mechanical calculations is the ability to evaluate bond breaking at larger strain values. Pursuant to this, the original $\mathrm{C} 4-\mathrm{Cl}^{\prime}$ distance of $7.52 \AA$ was increased to $13.10 \AA$ in 45 steps, representing a strain level of $75 \%$. Because of the large number of calculations, this phase of the work was limited to the AM1 method.

The plot of heat of formation as a function of $\mathrm{C} 4-\mathrm{Cl}^{\prime}$ distance is shown in Figure 8. It can be seen that the energy remains relatively constant up to a separation of about $11 \AA$, at which point it increases rapidly before leveling off at about 12 $\AA$. This is accompanied by an increase in energy of approximately $100 \mathrm{kcal} / \mathrm{mol}$, no doubt signifying the rupture of a covalent bond.

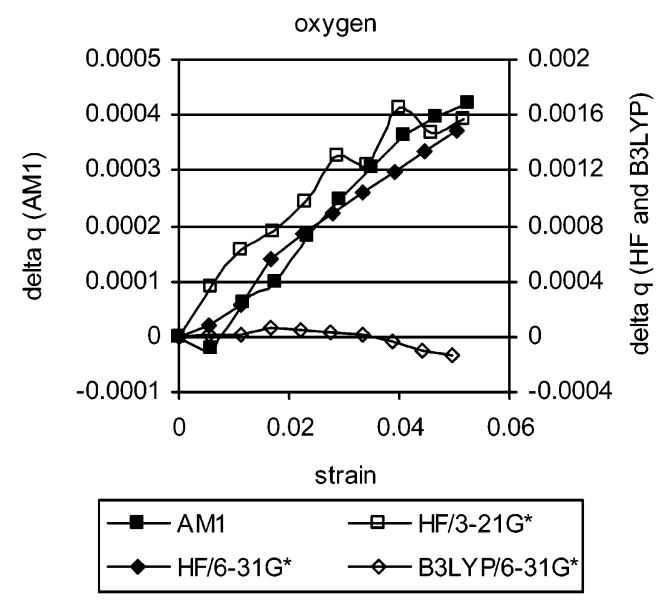

(a)

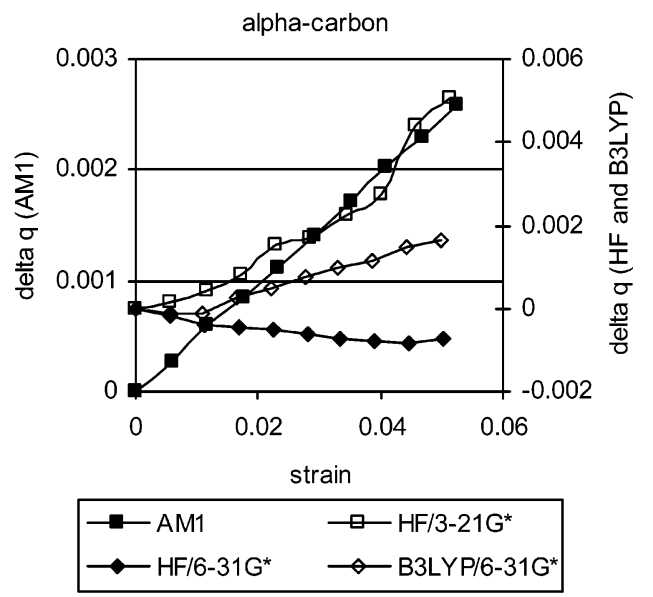

(b)

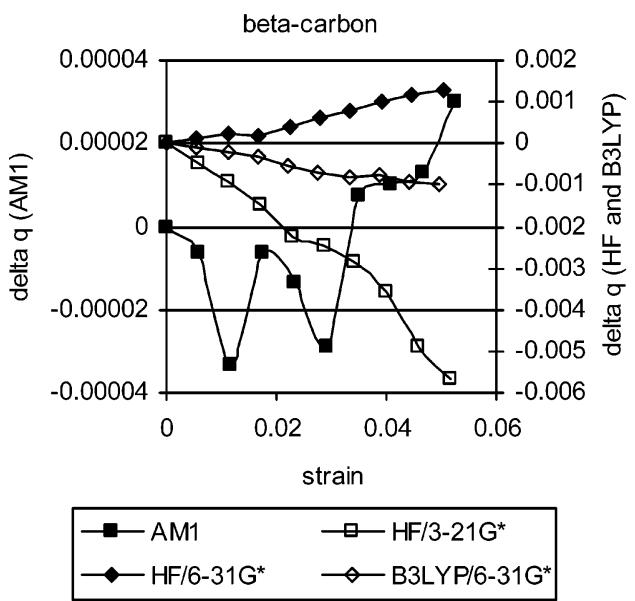

(c)

Figure 7. Changes in Mulliken charges as a function of strain.

An examination of the salient bond lengths (Figure 9) reveals that as the structure is strained, $\mathrm{C} 1-\alpha, \beta-\mathrm{O}$, and $\mathrm{O}-\mathrm{C}^{\prime}$ ' bonds gradually increase up to a $\mathrm{C} 4-\mathrm{Cl}^{\prime}$ distance of $11.83 \AA$, after which they shorten abruptly. In contrast, the $\alpha-\beta$ bond length mirrors the behavior of the heat of formation/distance curve, and exhibits a much larger distortion, on the order of $3 \AA$, as opposed to a few tenths of an angstrom for the other bonds.

Similarly, the $\mathrm{C} 1-\alpha-\beta$ bond angle (Figure 10a) increases gradually from $112^{\circ}$ before leveling off at about $142^{\circ}$. As before, the other bond angles increase gradually up to an extension of almost $12 \AA$, prior to a precipitous decrease. It can also be seen 


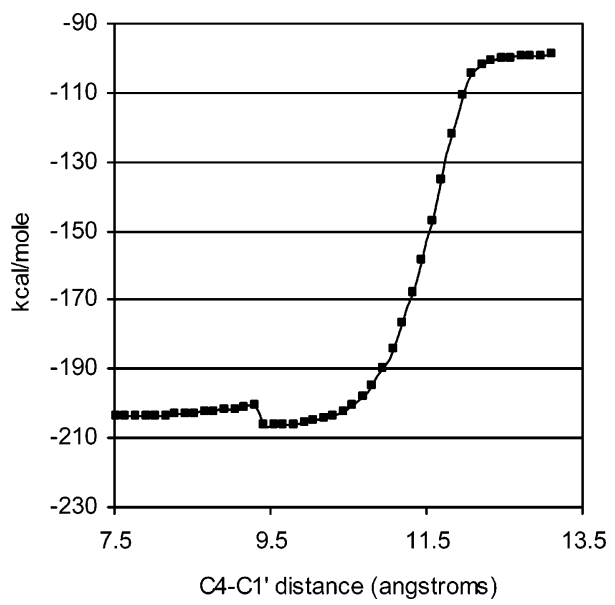

Figure 8. Results from AM1 calculations to $75 \%$ strain, heat of formation versus $\mathrm{C} 4-\mathrm{C}^{\prime}{ }^{\prime}$ distance.

that changes in the $\alpha-\beta-\mathrm{O}$ and $\beta-\mathrm{O}-\mathrm{C} 4^{\prime}$ (Figure 10b and $\mathrm{c}$ ) are much smaller than that in the $\mathrm{C} 1-\alpha-\beta$.

As might be expected, the behavior of the dihedral angles is much more complicated, probably due to the lower energies associated with rotations and the concomitant ability of such rearrangements to accommodate the structural changes that are occurring with such a large increase in the $\mathrm{C} 4-\mathrm{Cl}^{\prime}$ distance (Figure 11). With an increase of about $160^{\circ}$, the $\mathrm{C} 1-\alpha-\beta-\mathrm{O}$ dihedral angle exhibits the largest overall change, and it also noteworthy that there is a large sharp change from about $60^{\circ}$ at

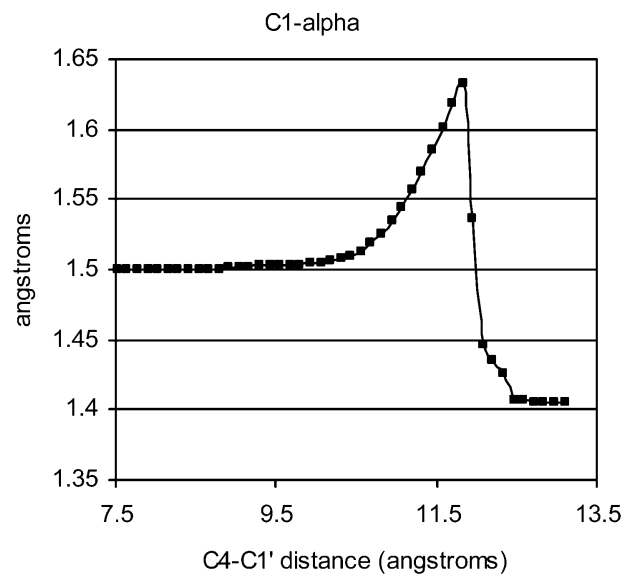

(a)

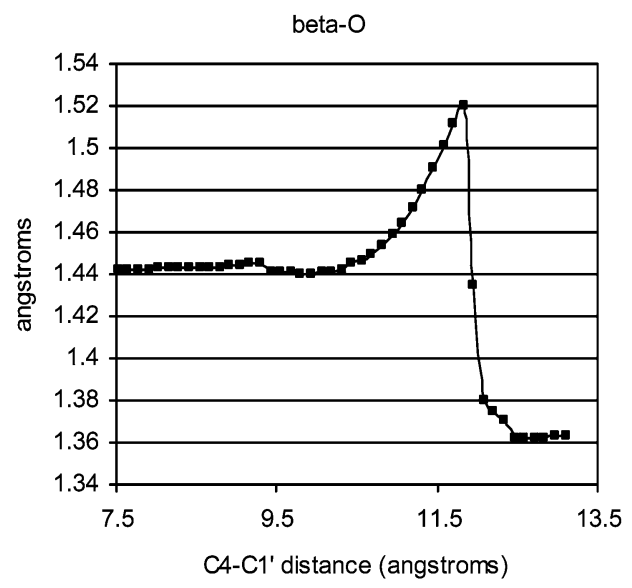

(c) a C4-C1' distance of $9.5 \AA$, and another smaller but still abrupt increase in the 11-12 $\AA$ range, corresponding to the point at which bond rupture may be occurring. While the other dihedrals are modified to smaller extents due to strain, they all show similar patterns of sharp changes at the same levels of strain. The rotations associated with the aromatic groups $(\mathrm{C} 2-\mathrm{C} 1-$ $\alpha-\beta$ and $\left.\beta-\mathrm{O}-\mathrm{C}^{\prime}-\mathrm{C}^{\prime}\right)$ also change quickly at about $10 \AA$, behavior that is not as obvious for the internal torsions. It is interesting that the $\alpha-\beta-\mathrm{O}-\mathrm{C}^{\prime}{ }^{\prime}$ twist has an almost regular pattern of increase and decrease with a period of about $2 \AA$.

These energetic and structural changes are further reflected in the electronic and orbital energy values (Figure 12). The HOMO and LUMO energies increase and decrease, respectively, to the largest extent at about $12 \AA$. It should also be noted that there is a small, but rapid increase at $9.5 \AA$. This pattern is repeated more apparently for the Mulliken charges of the oxygen and $\beta$-carbon. While the charge on the $\alpha$-carbon drops precipitously at the higher strain level, it is much more subtle at the lower value. Overall, the carbon atoms acquire partial negative charges, while the charge on the oxygen increases, but remains negative.

\section{Discussion and Conclusions}

Lignin and cellulose are integral components of the woody cell wall, and as such their properties are critical to chemical and physical behavior. Based on the importance of lignin, and the previously reported computational work on cellulose and

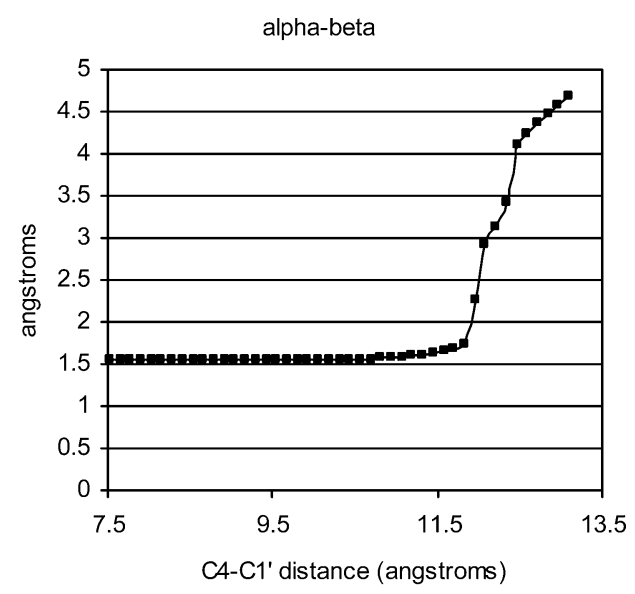

(b)

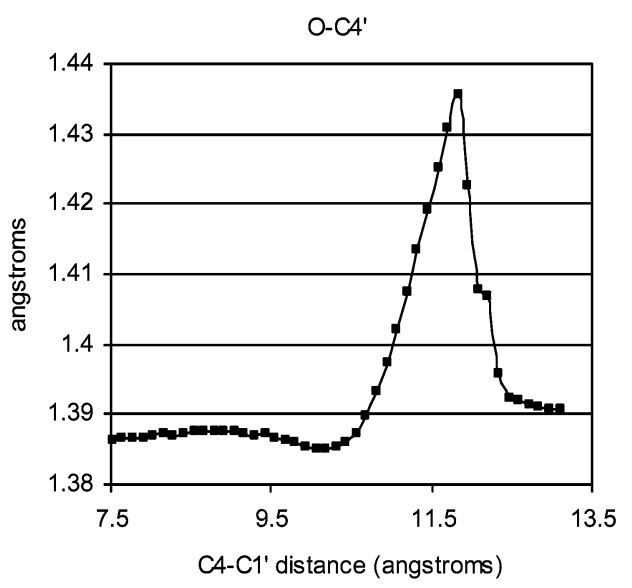

(d)

Figure 9. Bond lengths from AM1 calculations to $75 \%$ strain. 
(a)

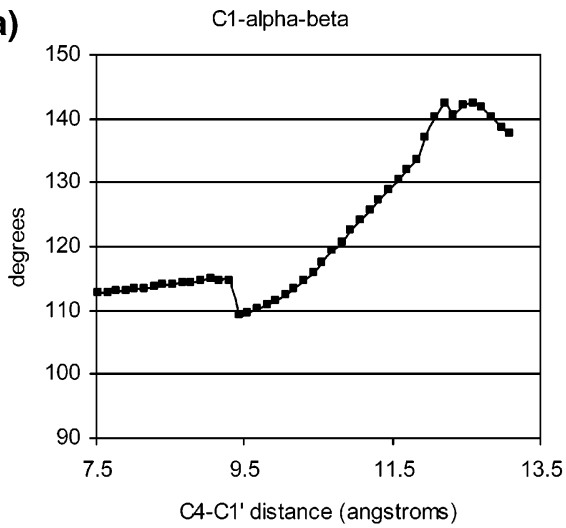

(b) $150 \quad$ alpha-beta-O

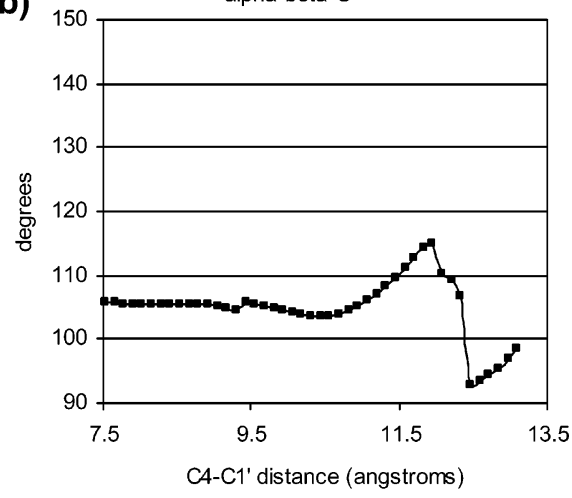

(c)

beta-O-C4'

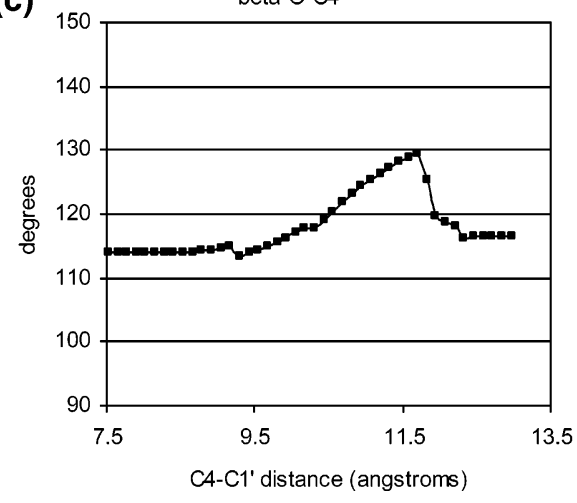

Figure 10. Bond angles from $A M 1$ calculations to $75 \%$ strain.

(a)

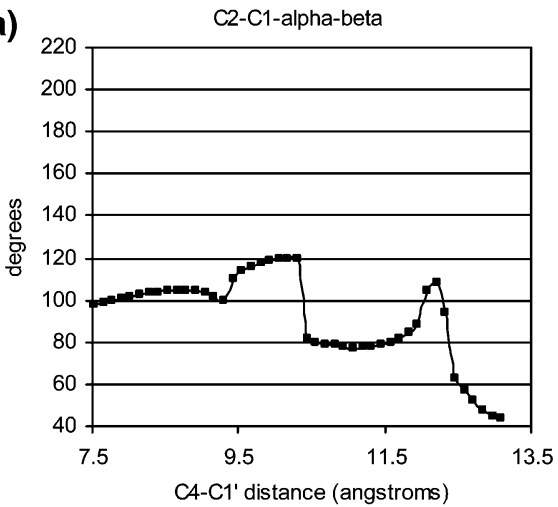

(c)

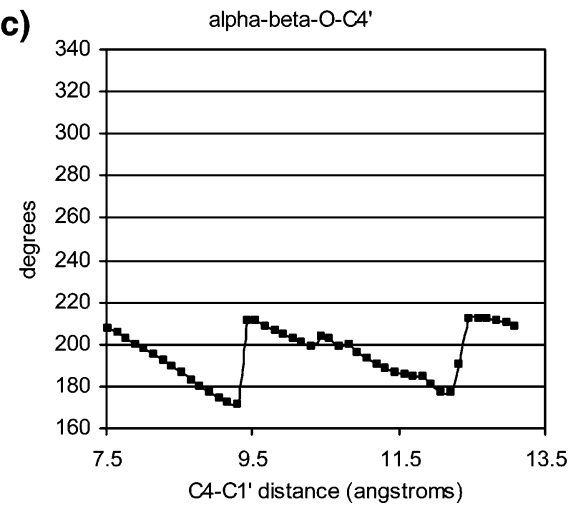

Figure 11. Dihedral angles from AM1 calculations to $30 \%$ strain.

synthetic polymers, the primary objective of the current work was to calculate Young's modulus for lignin, by the application of quantum chemical calculations. Based on a dimeric model compound and using a range of methods at varying levels of sophistication, this objective was successfully accomplished, resulting in the expected polynomial relationships for energy/ (b)

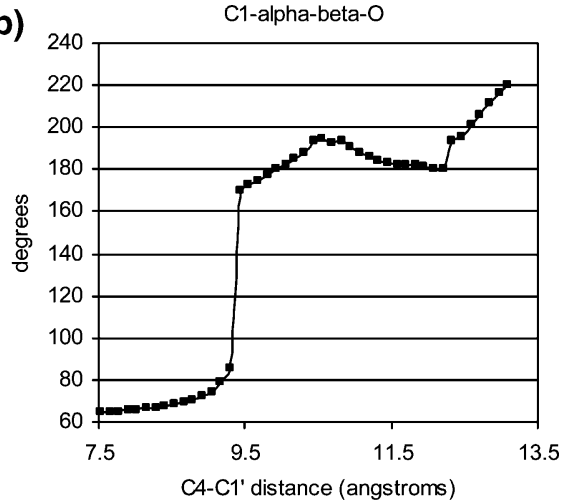

(d)

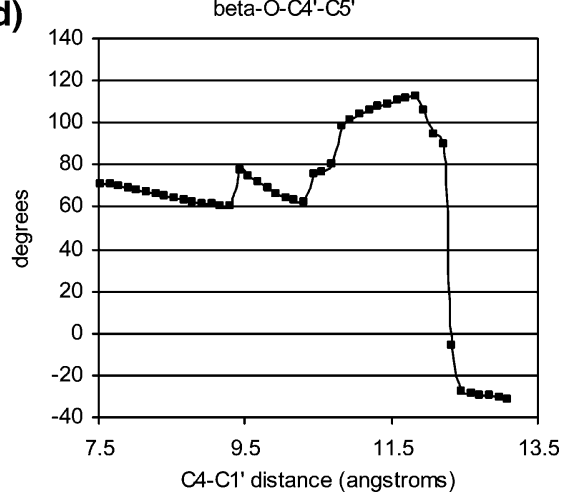

strain from which stress/strain curves were developed. The values for Young's modulus determined from the stress/strain curves are in good agreement with those from the experimental literature. While the model compound selected is, of necessity, much less complex than the lignin polymer, it is known from analytical work to be responsible for $50-60 \%$ of the polymer 


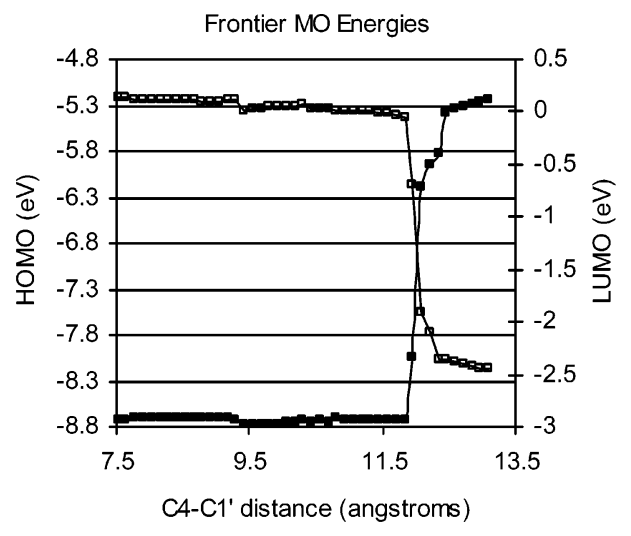

$\rightarrow-E H O M O(e V) \rightarrow-E L U M O(e V)$

(a)

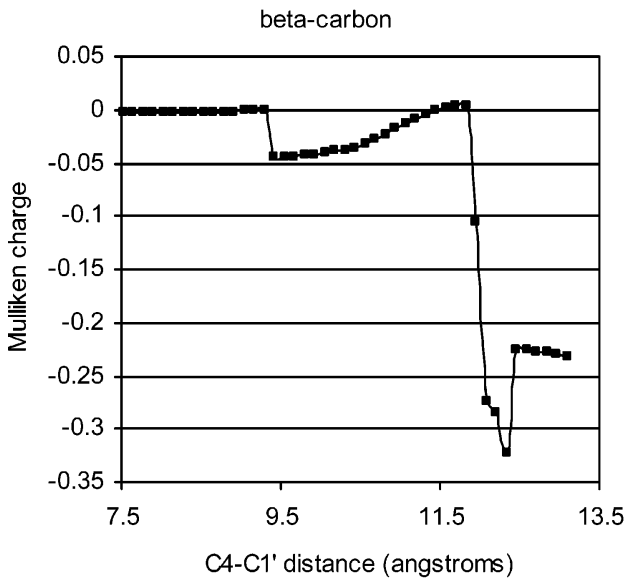

(c)

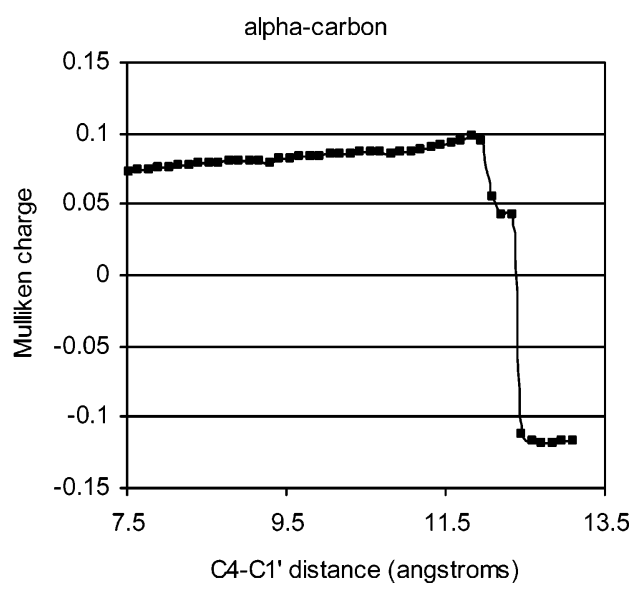

(b)

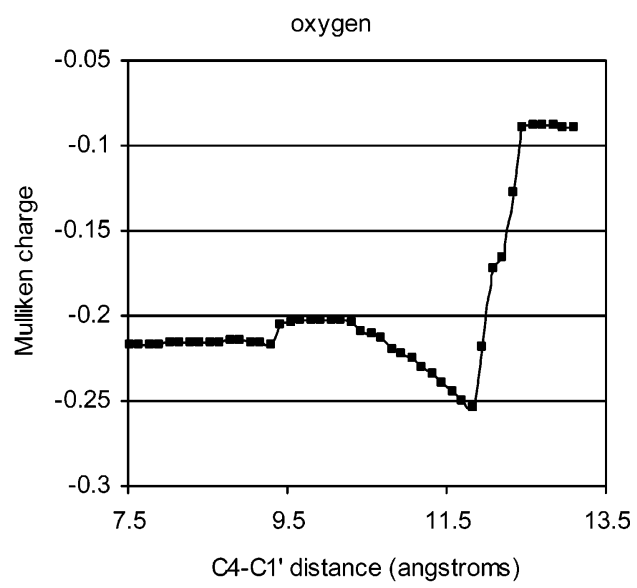

(d)

Figure 12. Results from AM1 calculations to $30 \%$ strain: (a) frontier molecular orbital energies, and (b)-(d) Mulliken charges.

and as such represented a logical choice for the current study. This structural similarity of the model to the polymer coupled with the correspondence between calculated and experimental values for Young's modulus combine to validate the selection of the model as a reasonable analogue for the macromolecule. In subsequent work, similar calculations will be performed on models representing other structures known to be present in the polymer itself.

Having established that Young's modulus could be determined with reasonable accuracy, an examination of changes in structure, charge, and frontier molecular orbital energies was initiated. The former were assessed to determine in detail the response of the structure to strain, while the latter would provide information on changes in reactivity. The fundamental nature of this work, notwithstanding, there are numerous technological and analytical applications in which the application of mechanical force may impact the behavior of lignin. These include vibratory-ball-milling for lignin isolation and high-yield pulping, which relies on mechanical action for the separation of wood fibers prior to pulping.

Not unexpectedly, bond lengths increased with strain, but to a relatively small degree, exhibiting about $1 \%$ increases in comparison to 5\% strain. It is apparent, therefore, that strain must be accommodated through changes in bond angles and dihedral angles. Among the former values, the largest and most linear changes are associated with the $\mathrm{C} 1-\alpha-\beta$ angle, indicating a close correspondence with strain. This may also be due to the overall structure of the model compound in which a linear strain between the terminal atoms becomes a bend centered at the $\mathrm{C} 1-\alpha-\beta$ bond angle. The torsional angles are similar to each other in terms of magnitude at about $4 \%$, and as such the rearrangements associated with twisting may be largely responsible for the changes in structure due to strain. The $\alpha-\beta-\mathrm{O}-$ $\mathrm{C}^{\prime}$ ' dihedral angle is quite linear with respect to strain, and as such may be interpreted as being closely coupled to the overall perturbation.

The consistent increases in HOMO energy and decreases in LUMO energy may be indicative of alterations in reactivity due to strain, and these terms may be of particular significance, because there is evidence that many of the technologically important reactions of lignin are due to orbital interactions. ${ }^{27}$ The mixed results for Mulliken charge are somewhat disappointing and raise questions about the utility of such calculations.

The observed differences among the computational methods, detailed in the results, notwithstanding, the general trends in structural changes are similar as are the frontier molecular orbital energies. Finally, and most importantly for the principal objectives of this Article, the values for Young's modulus are comparable across all of the methods used.

The results from the larger $(75 \%)$ strain experiments interestingly show that there are two points $(\sim 9.5$ and $11 \AA)$ at which structure, energies, and charge all change very sharply. At the former level of strain, rearrangements due to changes in dihedral angles are responsible for accommodating the increase in length. At $11 \AA$, while there are still modifications to bond angles and dihedral angles occurring, there is also a major increase in the 
$\mathrm{C}-\alpha$ to $\mathrm{C}-\beta$ bond length, ultimately reaching a distance in excess of $4.5 \AA$, indicative of bond cleavage. Intuitively, it might have been expected that one of the carbon-oxygen bonds would have been more susceptible to breakage, but the current study contradicts this assumption. More detailed work, at higher levels of theory, and a closer examination of each of the bonds in the interunit linkage will be undertaken to address this question. It is interesting to note that both carbon atoms acquire partial negative charges, possibly indicating a homolytic cleavage reaction. ${ }^{7}$ In previous computational work on cellulose, it was proposed that analogous bond ruptures would involve free radical reactions, and indeed unpaired electrons, in the form of mechano-radicals, have been detected in cellulose subjected to intense mechanical treatments. ${ }^{28,29}$

In summary, the computational methods and model compound used in this work result in values for Young's modulus that agree with the experimental literature. At low levels of strain, modifications in bond angle and dihedral angle appear to be important in accommodating the increase in overall length. At higher levels of strain, bond rupture can be detected structurally and energetically, occurring between the $\alpha$ and $\beta$ carbons, with the simultaneous acquisition of partial negative charge, possibly indicating a homolytic cleavage reaction. Subsequent work will concentrate on points of bond rupture and models representing other interunit linkages in the lignin polymer.

\section{References and Notes}

(1) Fengel, D.; Wegener, G. Wood-Chemistry Ultrastructure Reactions; Walter de Gruyter: Berlin, 1984; p 66.

(2) Sarkanen, K; Ludwig, C. Lignins-Occurrence, Formation, Structure and Reactions; Wiley-Interscience: New York, 1971; p 1.

(3) Meyer, K.; Lotmar, W. Sur l'élasticité de la cellulose. Helv. Chim. Acta 1936, 19, 68-86.

(4) Gillis, P. Elastic constants of cellulose. Cell. Chem. Tech. 1970, 4, $123-35$.

(5) Gillis, P.; Mark, R.; Tang, R. Elastic stiffness of crystalline cellulose in the folded-chain solid state. J. Mater. Sci. 1969, 4, 1003-07.

(6) Eichorn, S.; Young, R.; Davies, G. Modeling crystal and molecular deformation in regenerated cellulose fibers. Biomacromolecules 2005, 6, 507-513.

(7) French, A.; Johnson, G. Preliminary modulus and breakage calculations in cellulose models. National Cotton Council Beltwide Cotton Conference; San Antonio, TX, 2006; pp 2410-2417.

(8) Kroon-Batenburg, L.; Kroon, J.; Northolt, M. Chain modulus and intramolecular hydrogen bonding in native and regenerated cellulose fibers. Polym. Commun. 1986, 27, 290-292.

(9) Chen, W.; Lickfield, G.; Yang, C. Molecular modeling of cellulose in amorphous state. Part I. model building and plastic deformation study. Polymer 2004, 45, 1063-1071.

(10) Goldstein, H. Classical Mechanics; Addison-Wesley: Reading, MA, 1950; pp 348-349.

(11) Srinivasan, P. The elastic and thermal properties of timber. Q. J. Indian Inst. Sci. 1941, 4, 222-314.

(12) Cousins, W.; Armstrong, R.; Robinson, W. Young's modulus of lignin from a continuous indentation test. J. Mater. Sci. 1975, 10, 16551658.

(13) Cousins, W. Elastic modulus of lignin as related to moisture content. Wood Sci. Technol. 1976, 10, 9-17.
(14) Wimmer, R.; Lucas, B. Comparing mechanical properties of secondary wall and cell corner middle lamella in spruce wood. IAWA J. 1997, 18, 77-88.

(15) Salmén, L. Micromechanical understanding of the cell-wall structure. C. R. Biol. 2004, 327, 873-880.

(16) Davy, K.; Braden, M. Study of polymeric systems based on 2-2 bis4(2-hydroxy-3methacryloyloxypropoxy) phenyl propane. Biomaterials 1991, 12, 406-410.

(17) Wellons, J. The adherends. In Adhesive Bonding of Wood and Other Structural Materials; Blomquist, R., Christiansen, A., Gillespie, R., Meyers, G., Eds.; Educational Modules for Materials Science and Engineering, The Pennsylvania State University: University Park, PA, 1983; p 115.

(18) Peeters, A.; Van Alsenoy, C.; Bartha, F.; Bogár, F.; Zhang, M.-L.; Van Doren, V. Ab initio investigation of the Young's modulus of polyamide-6. Int. J. Quantum Chem. 2003, 91, 32-38.

(19) Katajiso, J.; Linnolahti, M.; Pakkanen, T. Ab initio studies on modulus of elasticity of modified polycarbonates. Chem. Phys. Lett. 2004 $385,25-28$.

(20) Winandy, J.; Rowell, R. Chemistry of wood strength. In Handbook of Wood Chemistry and Wood Composites; Rowell, R., Ed.; CRC Press: Boca Raton, FL, 2005; pp 303-347.

(21) Stomberg, R.; Lundquist, K. Stereochemistry of lignin structures of $\beta$-O-4 type. Crystal structures of model compounds. Nord. Pulp Pap. Res. J. 1994, 9, 43-47.

(22) Shao, Y.; Molnar, L.; Jung, Y.; Kussmann, J.; Ochsenfeld, C.; Brown, S.; Gilbert, A.; Slipchenko, L.; Levchenko, S.; O’Neill, D.; DiStasio, R., Jr.; Lochan, R.; Wang, T.; Beran, G.; Besley, N.; Herbert, J.; Lin, C.; Van Voorhis, T.; Chien, S.; Sodt, A.; Steele, R.; Rassolov, V.; Maslen, P.; Korambath, P.; Adamson, R.; Austin, B.; Baker, J.; Byrd, E.; Dachsel, H.; Doerksen, R.; Dreuw, A.; Dunietz, B.; Dutoi, A.; Furlani, T.; Gwaltney, S.; Heyden, A.; Hirata, S.; Hsu, C.-P.; Kedziora, G.; Khalliulin, R.; Klunzinger, P.; Lee, A.; Lee, M.; Liang, W.; Lotan, I.; Nair, N.; Peters, B.; Proynov, E.; Pieniazek, P.; Rhee, Y.; Ritchie, J.; Rosta, E.; Sherrill, C.; Simmonett, A.; Subotnik, J.; Woodcock, H., III; Zhang, W.; Bell, A.; Chakraborty, A.; Chipman, D.; Keil, F.; Warshel, A.; Hehre, W.; Schaefer, H.; Kong, J.; Krylov, A.; Gill, P.; Head-Gordon, M. Advances in methods and algorithms in a modern quantum chemistry program package. Phys. Chem. Chem. Phys. 2006, 8, 3172-3191.

(23) Márquez, J.; Núñez, J. On the determination of bond lengths by ab initio methods: estimation of errors and some improvements. THEOCHEM 2003, 624, 239-249.

(24) Hehre, W. Obtaining and using equilibrium geometries. Practical Strategies for Electronic Structure Calculations; Wavefunction Irvine, CA, 1995; pp 7-84, pp 193-204.

(25) Young, D. Computational Chemistry-A Practical Guide for Applying Techniques to Real World Problems; Wiley-Interscience: New York, 2001; pp 135-143.

(26) Rahal-Sekkal, M.; Sekkal, N.; Kleb, D.; Bleckmann, P. Structures and energies of D-galactose and galobiose conformers as calculated by ab initio and semiempirical methods. J. Comput. Chem. 2003, 24, 806-818.

(27) Elder, T.; McKee, M.; Worley, S. The application of molecular orbital calculations to wood chemistry. V. The formation and reactivity of quinone methide intermediates. Holzforschung 1988, 42, 233-240

(28) Hon, D. Formation and behavior of mechano-radicals in pulp cellulose. J. Appl. Polym. Sci. 1979, 23, 1487-1499.

(29) Kuzuya, M.; Yamauchi, Y.; Kondo, S. Mechanolysis of glucosebased polysaccharides as studied by electron spin resonance. J. Phys. Chem. B 1999, 103, 8051-8059.

\section{BM700663Y}

